\title{
Phenotypic and Genotypic Analysis of Rice Lesion Mimic Mutants
}

\author{
Mohammad Nurul Matin ${ }^{1}$, Devendra Pandeya ${ }^{1}$, Kwnag-Hyun Baek ${ }^{1}$, Dong Sun Lee ${ }^{2}$, Jai-Heon Lee, \\ Hoduck Kang ${ }^{4}$ and Sang Gu Kang ${ }^{1 *}$ \\ ${ }^{1}$ Department of Biotechnology, Yeungnam University, Gyeongsan 712-749, Korea \\ ${ }^{2}$ Rice Research Institute, Yunnan Agricultural University, Kunming 650201, China \\ ${ }^{3}$ Departemnt of Genetic Engineering, Dong-A University, Busan 604-714, Korea \\ ${ }^{4}$ Department of Environmental and Ecological Engineering, Dongguk University, Seoul 100-715, Korea \\ (Received on January 17, 2010; Accepted on February 25, 2010)
}

Lesion mimic mutant (LMM) plants display spontaneous necrotic lesions on their leaves without any pathogenic infection. Specific rice LMMs designated as spotted leaf (spl) including spl1, spl3, spl4, spl5 and spl6 are genetically known as lesion resembling disease (lrd) mutant. The inheritance patterns in the $F_{1}$ and $F_{2}$ progenies of these mutants are controlled by recessive genetic factors. Lesion development in the rice LMMs were controlled by both development stages and environmental factors. The rice LMMs exhibited higher numbers of spots under $45^{\circ} \mathrm{C}$ temperature than those under $30^{\circ} \mathrm{C}$. Contents of chlorophyll were drastically reduced at 60 days old LMM leaves when the spot formation was severe. The levels of endogenous hydrogen peroxide were highest at 45 days old mutants but reduced at 60 days old. Transcription levels of stress related genes including thioredoxin peroxidase and protein disulfide isomerase were reduced in spotted leaves than those of non spotted leaves. It could be suggested that scavenging system against reactive oxygen species induced by either stresses or innate metabolisms may not work properly in the rice LMMs. As these rice LMMs autonomously expressed clear lesions of $l r d$ phenotype without pathogen infection, it could be useful to understand stresses responses in plants.

Keywords : lesion, lesion mimic mutant, Oryza sativa, reactive oxygen species, spotted leaf

Plants exposed to stresses given by water, temperature, light, pathogen as well as metabolically generated reactive oxygen species (ROS) resulted in extensive formation of lesions on the leaves (Balague et al., 2003; Greenberg, 1996). However lesions are appeared spontaneously on the leaf surfaces of lesion mimic mutant (LMM) plants in the absence of any pathogenic infection. LMM plants in rice were specifically designated lesion resembling mutants (lrd).

\footnotetext{
*Corresponding author.

Phone) +82-53-810-3025, FAX) +82-53-816-8498

E-mail)kangsg@ynu.ac.kr
}

In most rice LMM plants, the reddish brown and dotted spot-like lesions are formed on their leaf surfaces and occasionally scattered throughout the plant body. These lesion formations on the plants were considered as symptoms by pathogenic infection. In the LMM mutants, however, these lesions are the cause of the spontaneous death of the localized cells without any pathogen or environmental stress exposures (Balague et al., 2003; Gray et al., 2002; Kang et al., 2007; Matin et al., 2006).

The ROS triggered cell death has been studied well which is an essential process to maintain tissue homeostasis in respect to developmental process (Greenberg, 1996; Mittler et al., 2004). In physiology, high accumulations of hydrogen peroxide and superoxide $\left(\mathrm{O}_{2}{ }^{\circ}\right)$ in and around the lesions have been identified in the LMMs and was concluded that ROS production in the cells is the causal agent for the cell death (Jabs et al., 1996; Lorrain et al., 2003). Several environmental factors such as humidity, light, day length, and temperature have been reported that modulated cell death and resistance response in the LMMs (Dietrich et al., 1994; Greenberg and Ausubel 1993; Jambunathan et al., 2001; Noutoshi et al., 2006; Yao et al., 2009). To protect themselves from the damaging effects of the stress elicitors, plants have evolved several physiological, biochemical and genetic mechanisms including hypersensitive response (HR), genetically determined programmed cell death (PCD), production of antioxidant, as well as structural adjustments of the cellular constituent. Most of these processes are characterized by rapid and spontaneous death of the localized cell at the site of stress introduction. These patterns of cell death and lesion formation have been studied in Arabidopsis (Bouchez et al., 2007; Dietrich et al., 1994; Jabs et al., 1996; Noutoshi et al., 2006), maize (Gray et al., 1997; Hoisington et al., 1982; Hu et al., 1998; Simmons et al., 1998), barley (Buschges et al., 1997; Rostoks et al., 2006; Wolter et al., 1993), wheat (Sugie et al., 2007), and rice (Kang et al., 2007; Liu et al., 2004; Mori et al., 2007; Yamanouchi et al., 2002; Yin et al., 2000).

For the identification of cell death mechanism, LMM plants provide useful models through the characterization 
of cell death initiation mutants because of their induction of genetically programmed cell death (Kang et al., 2007; Lorrain et al. 2003). However, less is known about the morphology, physiology, agronomical features as well as genetics of the LMM plants those might provide clue to understand the regulation of the programmed cell death for lesion formation. In this study, we have discussed the patterns of lesion formation in the rice LMMs with the effects of environmental condition and the phenotype on agronomic traits with genetic analysis of the mutants which may provide more fundamental features of disease responses of plants.

\section{Materials and Methods}

Plant materials. A total of 160 mutant lines and wild type rice (Oryza sativa L. ssp. japonica) were grown under natural field conditions between $30^{\circ} \mathrm{C}$ to $35^{\circ} \mathrm{C}$ in paddy field at Yeungnam University, Gyeongsan, Korea. Among them nine lines including spll, spl3, spl4, spl5 and spl6 were isolated as lesion mimic mutant plants which were generated by Ethyl methane sulphonate (EMS) treatment (Table 1). Spotted and newly grown non-spotted leaves from 60 days old plants were harvested, frozen with liquid nitrogen and stored at $-80^{\circ} \mathrm{C}$ until use for DNA and RNA extraction.

Phenotypic analysis. The time of spot formation as well as color, structure and arrangement of spots throughout the leaves at different developmental stages were documented. Several agronomic traits including days to heading (DH), tiller number (TN), culm length (CL), panicle exertion ability (PE), panicle length (PL), panicle number (PN), panicle thresh ability (PT), spikelet number (SN), spikelet fertility (SF) and 100 grains weight were evaluated from LMMs and wild type (Ilpoom byeo) plants. Most of the agronomic data were evaluated at 60 days after transplantation during the end of vegetative growth of the wild type rice plants. Fifteen plants of each accession were evaluated for each agronomic data. The number of tiller per plant was scored as the number of reproductive tillers for each plant. Average tiller number was calculated from the data obtained from fifteen plants. Average number of spikelets was measured from the 5 plants where 5 panicles were used from each plant. Spikelet fertility percentage was scored as the number of grains per panicle divided by the number of spikelets per panicle. The heading date for each plant of each accession was recorded when the first developing panicle emerged about $1 \mathrm{~cm}$ beyond the leaf sheath of the flag leaf. Heading time was monitored everyday. The mean days to heading of individuals were taken as heading date and days to heading $(\mathrm{DH})$ was converted from the day of transplantation to mean heading date. For grain weight, 100 ripped spikelets were dehulled and gram weight were measured.

Application of different environmental conditions. The experiment was conducted in a growth chamber with $14 \mathrm{~h}$ light and $10 \mathrm{~h}$ dark period, a photosynthetic photon flux density of $350 \mu \mathrm{mol} \mathrm{m} \mathrm{m}^{-2} \mathrm{~s}^{-2}$ with $28^{\circ} \mathrm{C} / 20^{\circ} \mathrm{C}$ day/night temperatures, and $65 \%$ relative humidity. To observe the effects of the temperature on severity of the phenotypic expression of the lesions, mutant plants were grown in growth chamber at $15^{\circ} \mathrm{C}, 30^{\circ} \mathrm{C}$, and $45^{\circ} \mathrm{C}$ temperature

Table 1. Several important agronomic traits of lesion mimic mutant plants in rice

\begin{tabular}{|c|c|c|c|c|c|c|c|c|c|c|c|c|c|c|}
\hline $\begin{array}{l}\text { LMM } \\
\text { Type }\end{array}$ & $\begin{array}{c}\text { Plant } \\
\text { ID }\end{array}$ & $\begin{array}{l}\text { Line } \\
\text { name }\end{array}$ & $\mathrm{DH} \pm \mathrm{SE}$ & $\mathrm{CL} \pm \mathrm{SE}$ & $\mathrm{LL} \pm \mathrm{SE}$ & $\mathrm{LW} \pm \mathrm{SE}$ & $\mathrm{TN} \pm \mathrm{SE}$ & PE & $\mathrm{PL} \pm \mathrm{SE}$ & $\mathrm{PN} \pm \mathrm{SE}$ & PT & $\mathrm{SN} \pm \mathrm{SE}$ & $\mathrm{SF} \pm \mathrm{SE}$ & $\mathrm{GW} \pm \mathrm{SE}$ \\
\hline Wild to & YUC044 & Suwon355 & $72+1$ & & & & & 1 & & & 1 & & & \\
\hline spl6 & YUM070 & Line 1177 & $73 \pm 2$ & & 29.2 & & & 1 & & & 5 & & & \pm .16 \\
\hline bl1 & YUM0 & Line 1187 & $76 \pm 4$ & $69.6=$ & 300 & & & 1 & & & 3 & 128 & & \pm .10 \\
\hline 015 & & F1 222 & $4 \pm 4$ & & & & & 3 & & & 3 & & & \pm .07 \\
\hline$p l 3$ & & & & & & & & 1 & & & 1 & & & \\
\hline plo & УUाM1 & & $96 \pm 5$ & & & & & 1 & & & 3 & & & \\
\hline pl6 & 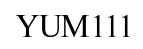 & & $92 \pm 4$ & $638+0$ & & $1.10 \pm .06$ & & 3 & & & 3 & & & $3.08 \pm .08$ \\
\hline spl6 & & & & & & & & 1 & & & 7 & & & $3.06 \pm .09$ \\
\hline$p l 3$ & & & & $42.8 \pm 0.8$ & & & & 3 & & & 1 & & & $1.98 \pm .08$ \\
\hline pl4 & YUM126 & Fl314 & $90 \pm 2$ & $68.0 \pm 0.7$ & $56.7 \pm 1.2$ & $1.52 \pm .07$ & $13 \pm 1.9$ & 3 & $13.1 \pm 1.04$ & $412 \pm 2.30$ & 3 & $76 \pm 6.66$ & $673.3 \pm 2.0$ & $1.72 \pm .08$ \\
\hline
\end{tabular}

Note: wild type cultivar (Ilpoombyeo), DH; days to heading (defined as duration from transplantation to emergence of the first panicle), CL, culm length in centimeter $(\mathrm{cm})$, LL; leaf length in $\mathrm{cm}, \mathrm{LW}$; leaf width in $\mathrm{cm}, \mathrm{TN}$; number of reproductive tiller per plant, PE; panicle exsertion ability (Scale: 1; well exserted, 3; moderately well exserted, 5; just exserted, 7; partly exserted, 9; enclosed ), PL; panicle length in cm, PN; panicle number per plant, PT; panicle thresh ability [Firmly grasp and pull the hand over the panicle and estimate the percentage of shattered grains. Scale: 1; difficult (less than 1\%), 3; moderately difficult (1-5\%), 5; intermediate (6-15\%), 7; loose (26-50\%), 9; easy (51-100\%). SN; spikelet number per panicle, SF; spikelet fertility percentage per plant, GW; 100 grains weight in gram, SE; standard error of five observation for each trait. 
having $14 \mathrm{~h}$ light and $10 \mathrm{~h}$ dark, a photosynthetic photon flux density of $350 \mu \mathrm{mol} \mathrm{m} \mathrm{m}^{-2} \mathrm{~s}^{-2}$ with $50 \%$ relative humidity from 30 days to 60 days old. The data of spot formation time was observed from the beginning. In another experiment, seedlings were treated with $100 \mathrm{mM} \mathrm{NaCl}$ and $1 \mathrm{mM}$ salicylic acid (SA) and then they were recovered from stresses by allowing normal environmental conditions and were further grown in the pots. Beside, non treated controls also were grown. At 60 days of the plant age the data of spot intensity was observed and flag leaves were photographed. Spot number was counted using simple Olympus SZ61 microscope (Olympus, Japan) at 0.67X magnification. Total spot number was taken from ten microscopic fields where each field covering $1.7 \mathrm{~cm}$ length and full width of the leaf. Average number of spots was calculated from five leaves of each plant.

\section{Reverse transcription PCR analysis and CDNA cloning.} To analyze the expression of oxidative stresses related genes before and after the formation of spots on the mutant leaves of the LMM plants, total RNAs were extracted from spotted flag leaves and newly formed nonspotted leaves of LMM plants and flag leaves of wild type rice (Ilpoom byeo) at 60 days old of plant age. Reverse transcription polymerase chain reaction (RT-PCR) was performed as described (Lee et al., 2007), with modifications. Briefly, a first strand cDNA was synthesized with the Universal Riboclone ${ }^{\circledR}$ cDNA Synthesis kit (Promega, USA) according to the manufacturer instructions. The first strand cDNA fragments, used as a template, corresponding to thioredoxin peroxidase (OsTPX, accession; AM039889), protein disulfide isomerase (OsPDI, accession; AY987391), catalase (OsCAT, accession; AY339372) and YABBY (OsYABBY, accession; XM_469012) were amplified by PCR. Thermal cycling using Taq DNA polymerase (Promega) were as follows: denaturation at $95^{\circ} \mathrm{C}$ for $2 \mathrm{~min}$, followed by 29 cycles of denaturation at $95^{\circ} \mathrm{C}$ for $1 \mathrm{~min}$, annealing at $55^{\circ} \mathrm{C}$ for $2 \mathrm{~min}$ and extension at $72^{\circ} \mathrm{C}$ for $2 \mathrm{~min}$, with an elongation step of $72^{\circ} \mathrm{C}$ for $5 \mathrm{~min}$. The specific primers were as follows, OsPDI-183F, 5'-CGT CGA GTT CTA CGC CCC GTG-3'; OsPDI-987R, 5'-CAG CCC AAA GTA CTG GAA GGC-3', OsTPX-1F, 5'-ATG GCC GCC TGC TGC TCC TCC-3'; OsTPX-786R, 5'-TTA GAT GGC CGC GAA GTA CTC-3' ,OsCAT-1F, 5'-ATG GAT CCC TAC AAG CAC CGC-3'; and OsCAT-1478R, 5'-TTA CAT GCT CGG CTT CGC GCT-3' and OsYabby-1F, 5'-GCC ATA TCT ATC TTT CTA GCT-3'; OsYabby-1020R, 5'CTG TCA TAC GTG CGT CGA CAC-3' (F; forward, R; reverse). Amplified and purified PCR products were cloned into pGEM-T Easy vector (Promega). Nucleotide sequencing was performed by Bigdye termination method using ABI 3700 DNA analyzer (Applied Biosystem, Hitachi,
Ltd.) at Molecular Genetics Laboratory, Department of Biotechnology, Yeungnam University, Gyeongsan, Korea.

Northern blot analysis. Northern blot analysis was performed using a described method (Kang et al., 2004). Briefly, $20 \mu \mathrm{g}$ of total RNA was electrophoretically separated on 1.4\% denaturing agarose gel using 1X MOPS [3(N-morpholino)-propanesulfonic acid] buffer and transferred to Nytran ${ }^{\circledR}$ nylon membranes (Schleicher \& Schuell Bioscience, USA) with $25 \mathrm{mM}$ sodium phosphate buffer (pH 7.0) for $12 \mathrm{~h}$. The membranes were exposed in UV at 1200J. Radioactive labeled probes were generated from the PCR amplified OsPDI, OsTPX/OsCAT and OsYABBY genes by random labeling system (Promega). Prehybridization was performed at $42{ }^{\circ} \mathrm{C}$ for $3-4 \mathrm{~h}$ in $50 \%(\mathrm{v} / \mathrm{v})$ formamide, 6X SSC (1X SSC is $0.15 \mathrm{M} \mathrm{NaCl}, 0.25 \mathrm{M}$ $\mathrm{NaH}_{2} \mathrm{PO}_{4}$ and $25 \mathrm{mM} \mathrm{Na} \mathrm{NDTA}_{2}$ ), 5X Denhardt's solution $[1 \%(\mathrm{w} / \mathrm{v})$ Ficoll, 1\% (w/v) polyvinylpyrrolidone, 1\% (w/v) bovine serum albumin], 0.5\% (w/v) SDS, and $0.1 \mathrm{mg} / \mathrm{mL}$ Herring sperm DNA. Hybridization was performed with $\alpha$ $\left[{ }^{32} \mathrm{P}\right] \mathrm{dCTP}$ labeled probe at $42^{\circ} \mathrm{C}$ for $14 \mathrm{~h}$. After hybridization, the membranes were washed twice in $2 \mathrm{X} \mathrm{SSC}$ and $0.1 \%$ SDS solution for $5 \mathrm{~min}$, followed by washing in $1 \mathrm{X}$ SSC and $0.1 \%$ SDS solution for $10 \mathrm{~min}, 0.1 \mathrm{X}$ SSC and $0.1 \%$ SDS solution for $20 \mathrm{~min}$ at room temperature. Finally, the membranes were washed in $0.1 \mathrm{X}$ SSC and $0.1 \%$ SDS solution at $42^{\circ} \mathrm{C}$ for $5 \mathrm{~min}$ and were exposed to X-ray film (Fuji photo film Co., Japan) for autoradiography. Northern blot analysis was carried out independently twice in this study.

Leaf anatomy. For the light microscopic study, thin sections of wild type leaf, newly grown non-spotted and spotted flag leaves of the LMMs from 60 days old plants were observed. Transverse free hand sections were cut from the leaf materials using a sharp razor, mounted in water and observed on Olympus BX51 dissecting fluorescent microscope (Olympus, Japan). Observation were made under bright light, then subsequently under UV using a $365 \mathrm{~nm}$ excitation filter and a $488 \mathrm{~nm}$ long pass emission filter. Photographs were taken using an Olympus C-7070 digital camera (Olympus).

Chlorophyll content measurement. Mutant and wild type samples were collected at three differential developmental stages including nonspotted stage, spot initiation stage and severe spots and cell death stage represented for 15, 30, 45 and 60 days after transplantation, respectively. Chlorophyll content of the sample leaves were measured using a spectrophotometer with the following procedure. Fresh and fully expand $20 \mathrm{mg}$ leaf tissue was extracted with $1 \mathrm{ml}$ of $95 \%$ ethanol in a tube at $60^{\circ} \mathrm{C}$ for overnight. The extract was 
measured at wavelengths of both 645 and $663 \mathrm{~nm}$ with an Optizen2120 UV Spectrophotometer (Mecasys Co. Ltd. Korea). Chlorophyll $a$, chlorophyll $b$ and total chlorophyll contents were calculated using MacKinney's (1941) specific absorption coefficients as described by Chory et al., (1989) in which chlorophyll $a=12.72\left(\mathrm{~A}_{663}\right)-2.59\left(\mathrm{~A}_{645}\right)$, chlorophyll $b=22.88\left(\mathrm{~A}_{645}\right)-4.68\left(\mathrm{~A}_{6663}\right)$, and total chlorophyll $=20.29\left(\mathrm{~A}_{645}\right)+8.02\left(\mathrm{~A}_{663}\right)$. The total chlorophyll per gram tissue was converted with the formula of chlorophyll $(\mathrm{mg} /$ $\mathrm{g})=$ chlorophyll $(\mathrm{mg} / \mathrm{L}) \times 0.001(\mathrm{~L}) /$ fresh weight $(\mathrm{g})$. Three biological replicates were used for this experiment.

Hydroperoxides measurement. The Concentration of hydroperoxides $\left(\mathrm{H}_{2} \mathrm{O}_{2}\right)$ was determined using the method of Brennan and Frenkel (1977). Briefly, two grams of fresh leaves from 15, 30, 45 and 60 days old plants of wild type and mutant were homogenized in $10 \mathrm{~mL}$ of cold acetone and centrifuged at $10,000 \times g$ for $10 \mathrm{~min}$. Supernatant was collected. One $\mathrm{mL}$ of the supernatant was mixed with 0.1 $\mathrm{mL}$ of $20 \%$ titanic tetrachloride in concentrated $\mathrm{HCl}, \mathrm{v} / \mathrm{v}$, and $0.2 \mathrm{~mL}$ of concentrated $\mathrm{NH}_{4} \mathrm{OH}$ to precipitate the peroxide-titanium complex. After the precipitate was formed, the reaction mixture was centrifuged at $10,000 \times g$ for 10 min. The supernatant was discarded and the resulting pellet was dissolved in $0.75 \mathrm{~mL}$ of $2 \mathrm{~N} \mathrm{H}_{2} \mathrm{SO}_{4}$ and the absorbance was measured at $415 \mathrm{~nm}$ against a water blank using an Optizen2120 UV Spectrophotometer (Mecasys Co. Ltd. Korea). The concentration of the $\mathrm{H}_{2} \mathrm{O}_{2}$ in the extracts was calculated by comparing the absorbancy against a standard curve representing titanium- $\mathrm{H}_{2} \mathrm{O}_{2}$ complex from 0.1 to 1 $\mathrm{mM}$. Experiment was conducted thrice independently.

Genetic analysis. Among the LMMs, spl1, spl3, spl4, spl5 and spl6 were studied to understand their inheritance pattern. All the mutants were used as female parents and were crossed with indica and japonica type pollen donor. The mutant spll was crossed with Ansanbyeo (japonica) and Milliang23 (indica), spl4 and spl5 was crossed with Ilpoom (japonica) and Milliang23 (indica), spl3 was crossed with Aroombyeo (indica) and spl6 was crossed with Donghaechal (japonica) and IRRI347 (indica). Resulted $\mathrm{F}_{1} \mathrm{~S}$ were self fertilized to produce $\mathrm{F}_{2}$. Large number of individual $\mathrm{F}_{2}$ progenies were grown in the field and phenotypic data of segregation of mutant and wild type traits were analyzed. From the $\mathrm{F}_{3}$ phenotypic data, genotype of the $\mathrm{F}_{2}$ population were determined based on segregation of LMM phenotype.

\section{Results}

Agronomic characteristics of the rice LMMs. To understand the agronomic features of the rice LMM, several important agronomic traits were observed in the mutants as well as wild type plant over three cropping seasons. Apart from the spotted phenotypes, there were significant differences between the LMM lines. Among the mutant lines, several agronomic traits including days to heading, plant stature, tillering ability, leaf structures, grain structure and quality, and panicle structure were significantly different. Various agronomic traits of the mutants were analyzed to compare with the wild type and within the mutants. Most of the LMMs showed abnormal developmental phenotypes with various degrees of agronomic characters and significant lower trait values than the control. Even among mutants, those traits varied significantly (Table 1). The LMMs exhibited a life span that was significantly shorter than those of the wild type control grown in same environmental conditions. They may as a result of early senescence due to cell death that affecting grain quality and maturation. In most cases, plant stature, tillering ability, panicle formation ability were lower than the control. Because of early senescence in the photosynthetic machinery of the mutants, most LMMs had a lower seed setting rate than the control (Table 1). Interestingly, the lines with more highly expressed lesion-mimic phenotypes exhibited significantly lower grain yields than those with the normal phenotype of wild type rice. However, seed germination ability was not different among mutants and wild type.

Genetic analysis of the LMMs. Genetic natures of the spl1, spl3, spl4, spl5 and spl6 among rice LMMs was established from the phenotypes of the parents, $F_{1}$ and $F_{2}$ segregation of cross between mutants and/or wild type cultivars as indicated in the Table 2 . All of the $F_{1}$ hybrids obtained from different crosses had wild type phenotype regarding spot formation in the leaves. $F_{2}$ progenies were segregated phenotypically at 3:1 ratio with wild type to lesion mimic mutants (Table 2). The segregation in the $F_{2}$ progeny of the cross between spll and two wild types followed 3:1 ratio having $\chi_{3: 1}^{2}$ value of 2.94 and 2.29 ( $p$ value, $0.10-0.05$ and $0.90-0.10$ ). While the $\chi_{3: 1}^{2}$ value for spl4, spl5 and spl6 from the cross with japonica type cultivars was $1.22,1.52$ and 2.20, respectively, as well as for spl3, spl4, spl5 and spl6 from the cross with indica type cultivars was $1.99,0.39,1.47$ and 0.53 , respectively, with 0.90-0.10 $p$-value (Table 2). Results of inheritances pattern in the $F_{1}$ and $F_{2}$ indicating, data fits to a given ratio of $3: 1$ for the null hypothesis that spll, spl3 spl4, spl5 and spl6 of LMMs are controlled by single recessive genes (Table 2). Furthermore, the genotype segregation of the $\mathrm{F}_{2}$ was determined. At least 20 seeds from each $F_{2}$ were grown and phenotyped. Based on no segregation with wild type phenotype, segregation with wild type and mutant phenotype and no segregation with mutant phenotype among the 20 plants, 
Table 2. Inheritance pattern of the LMMs

\begin{tabular}{|c|c|c|c|c|c|c|}
\hline \multirow{2}{*}{ Cross combination } & \multirow{2}{*}{ Type } & \multicolumn{3}{|c|}{ Segregation at $\mathrm{F}_{2}$} & \multirow{2}{*}{$\begin{array}{c}\chi^{2}(3: 1) \\
d f=1\end{array}$} & \multirow{2}{*}{$P$-value } \\
\hline & & $\mathrm{Wt}$ & Mutant & Total & & \\
\hline spl1/ Ansanbyeo & $\mathrm{J} / \mathrm{J}$ & 64 & 31 & 95 & 2.94 & $0.10-0.05$ \\
\hline spl1/ Milliang23 & $\mathrm{J} / \mathrm{I}$ & 47 & 23 & 70 & 2.29 & $0.90-0.10$ \\
\hline spl3/ Aroombyeo & $\mathrm{J} / \mathrm{I}$ & 40 & 19 & 59 & 1.99 & $0.90-0.10$ \\
\hline spl4/ Ilpoombyeo & $\mathrm{J} / \mathrm{J}$ & 105 & 42 & 147 & 1.22 & $0.90-0.10$ \\
\hline spl4/ Milliang23 & $\mathrm{J} / \mathrm{I}$ & 77 & 29 & 106 & 0.39 & $0.90-0.10$ \\
\hline spl5/ Ilpoombyeo & $\mathrm{J} / \mathrm{J}$ & 135 & 36 & 171 & 1.52 & $0.90-0.10$ \\
\hline spl5/ Milliang23 & $\mathrm{J} / \mathrm{I}$ & 87 & 36 & 123 & 1.47 & $0.90-0.10$ \\
\hline spl6/ Donghaechal & $\mathrm{J} / \mathrm{J}$ & 57 & 26 & 83 & 2.20 & $0.90-0.10$ \\
\hline spl6/ IRRI347 & $\mathrm{J} / \mathrm{I}$ & 124 & 36 & 160 & 0.53 & $0.90-0.10$ \\
\hline
\end{tabular}

Note: Phenotype of female parent was mutant, and pollen donor and all obtained $\mathrm{F}_{1}$ was wild type. J, japonica; $\mathrm{I}$, indica. Degree of free$\operatorname{dom}(d f)$ is 1 . All values that serve to fail to reject the null hypothesis.

they were considered as homozygous dominant, heterozygous and homozygous recessive, respectively. Then, the goodness of fit of the data was tested by $\chi^{2}$ analysis and found it follows 1:2:1 (homozygous dominant: heterozygous: homozygous recessive) genotype segregation ratio $\left(\chi_{1: 2: 1}^{2}=1.45,0.5<P>0.9\right)$ at $F_{2}$ generation. Results confirmed the genotype segregation of spll, spl3 spl4, spl5 and spl6 mutants followed the Mendelian inheritance with recessive nature.

Differential lesion phenotypes of LMMs without pathogen infection. The selected rice LMMs including spll, spl3, spl4, spl5 and spl6 exhibited different lesion phenotypes varying in the time of initiation and size and color of lesions without any pathogen infection (Fig. 1A). Briefly, the spll formed small dotted necrotic lesions. Mutant spl3 showed more than $10 \mathrm{~mm}$ in diameter round or smearing, yellowish black chlorotic lesions. The other mutants, both spl4 and spl5 displayed about $5 \mathrm{~mm}$ in diameter, discrete necrotic lesions, whereas spl4 showed reddish black elongated lesions. Small specks formation become visible as tiny dot that aggregate together with the plant age and form longitudinal lines parallel with the mid-rib in spl6 mutant. Formation of lesions in the mutant leaves was observed controlled by a developmental pattern where visible lesions appeared at the early developmental stage, which is 2 weeks after sowing, in spll, spl4 and spl5, whereas lesions were seen at seedling stage, which is 2 weeks after transplantation, in spl3. However, small flecks of dotted spots were appeared in spl6 at early milk stage, which is around 6 weeks after transplantation. The spl6 did not show lesion formation in the mid rib region whereas, the spll had the tendency to form lesions very rapidly along the mid rib of
A.

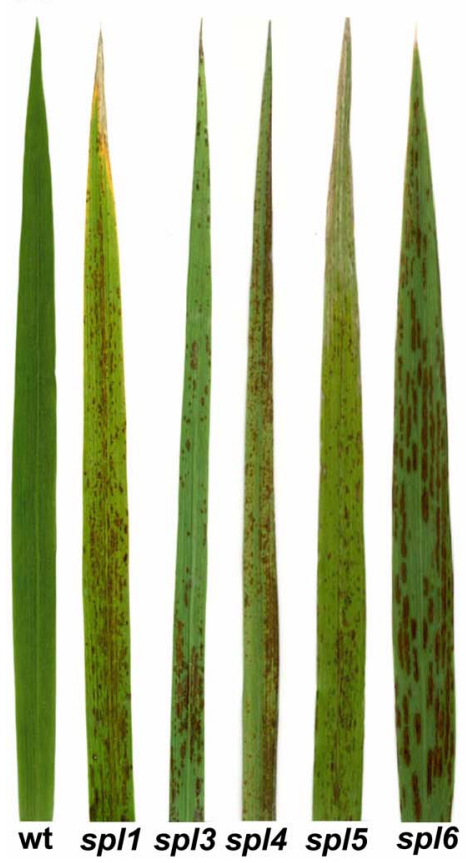

B.

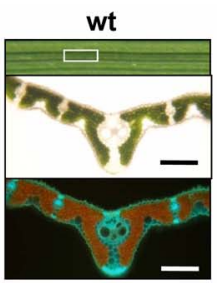

$s p / 3 s p$

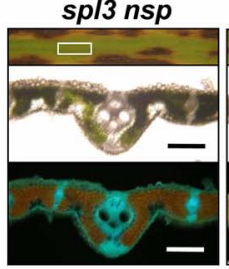

sp/5 nsp

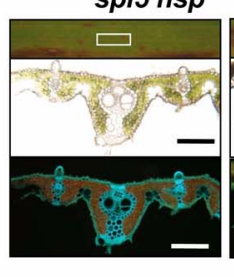

sp/5 sp

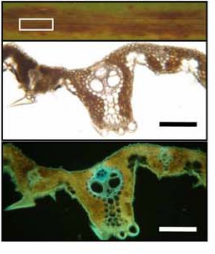

spl1 nsp

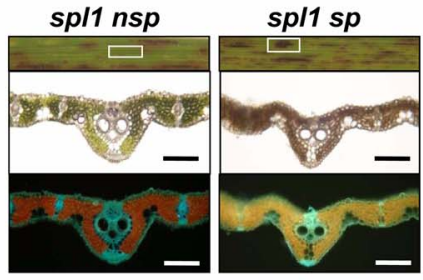

sp/4 nsp

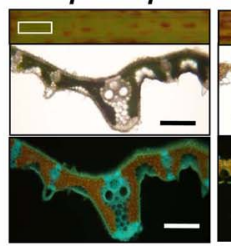

spl6 nsp

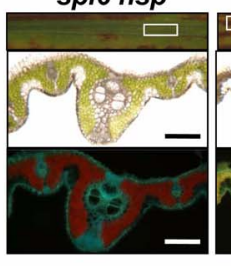

spl4 sp

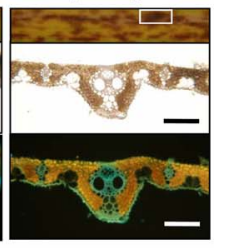

sp/6 sp

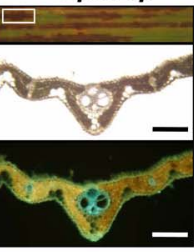

Fig. 1. Phenotypic expression of lesion mimic mutants (LMM). (A) Spotted leaves of different LMMs of rice. Wild type; leaf of wild type rice japonica cv. Ilpoombyeo, spl1, spl3, spl4, spl5 and spl6 leaves. Sixty days old flag leaves of plants grown in natural field condition were used. (B) Microscopy analysis of spotted and non-spotted leaf blades of the LMMs and the wild type leaf blades. Transverse sections observed under white light (upper panel) and UV light at $488 \mathrm{~nm}$ (lower panel). Non spotted (nsp) and spotted (sp) leaves at 60 days old plants were used for sectioning. Bars indicate $100 \mu \mathrm{m}$. 
the leaves (Figs. 1A). The interesting features was observed that the spots start expressing only at a certain period of developmental stage of the plant indicating that the expression of spot formation trait is developmentally controlled. This type of lesion formation was similar to lesion development in maize (Hu et al., 1998). In severely affected plants of spll, lesions were scattered over leaf sheathes and even over glumes of the spikelets. Finally, the leaves of the spll plant became rolled and the plants died earlier than the normal plants.

Anatomical features of the leaves of the rice LMMs. To observe the differences of the mesophyll chloroplast in the wild type and mutant leaves, we performed the microscopic analysis using fluorescent light without and with UV emission at $488 \mathrm{~nm}$ under a light microscope (Fig. 1B). In the sections of the wild type leaf, as well as the non-spotted part of the mutant leaf, the mesophyll cells between the vascular bundles were green and filled with chloroplasts (Fig. 1B). In the spotted part of the most mutant leaf sections, however, the mesophyll cells were dark brown with very few greenish parts (Fig. 1B), indicating lack of chlorophyll contents of the mesophyll cells because of chloroplast disruption in the lesion developed area in spotted leaves. When we observed the cross sections of leaves under the UV light emission at $488 \mathrm{~nm}$, the color reflections among leaf sections showed clear differences (Fig. 1B). The mesophyll cells of wild type and non-spotted part of rice LMM leaves were reddish under the UV light at $488 \mathrm{~nm}$, whereas mesophyll cells of spotted area of the most rice LMM leaves reflect brown or yellow colors. This indicated the lacking of chlorophyll resulted from the degradation of the chloroplasts in the mesophyll cells due to the lesion development (Fig. 1B).

Chlorophyll contents in the leaves of rice LMMs. In our previous study with transmission electron microscopy analysis, we observed that chloroplasts were disrupted in lesion promoting stage and was either absent or severely damaged in the spotted leaf 6 mutant (Kang et al., 2007). Furthermore, because most lesion formation area on the leaves of the rice LMMs turned brown color under UV light (Fig. 1B), we measured the relative amount of chlorophyll in leaves of the LMMs and wild type rice. The content of chlorophyll $a$ and chlorophyll $b$ were measured from the ethanol extract of leaf tissue using spectrophotometer at 645 and $663 \mathrm{~nm}$ wavelengths and total chlorophyll was calculated. The total chlorophyll content revealed significant differences among the mutant and wild type related to stage of spot development. At early stage, there were almost the same amounts of chlorophyll among all samples. Chlorophyll contents in the leaves of the wild type were

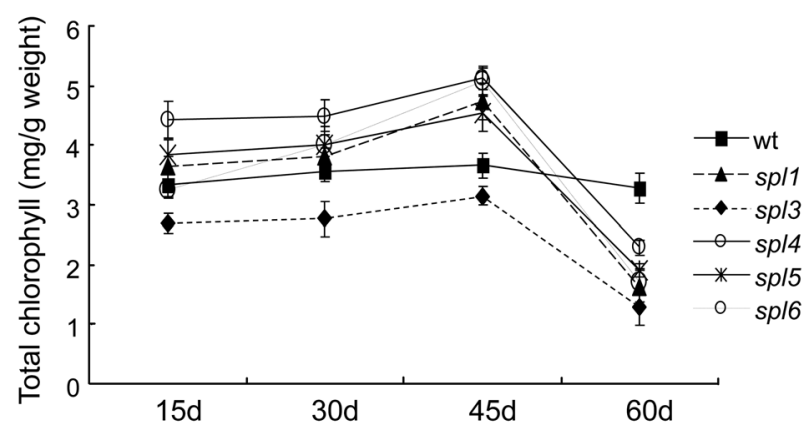

Fig. 2. Relative total chlorophyll content in the LMMs compared to the wild-type plants grown under normal environmental conditions. Fully expanded fresh leaves of 15, 30, 45 and 60 days old plants were used. Concentrations are expressed as $\mathrm{mg} / \mathrm{g}$ fresh tissue. Values are average of three replicates $($ mean $\pm \mathrm{SD})$.

increased up to $45 \mathrm{~d}$ old and then reduced at $60 \mathrm{~d}$ old with non significant differences (Fig. 2). However, amount of chlorophyll in the leaves of the rice LMMs were drastically reduced at 60 days old when severe spots formed on the LMM leaves (Fig. 2). Interestingly, chlorophyll reduction was particularly more pronounced in the spl4 and spl6. High amount of chlorophyll was present in the spl4 from the early stage and reduced after 45 days old. Moreover, less amounts of chlorophyll at 60 days old spotted leaves of most rice LMMs were correlated with the lackage of chlorophyll observed under UV light (Fig. 1B).

\section{Effect of temperature and light on lesion formation on} the leaves of rice LMMs. To observe the effects of temperature on severity of the phenotypic expression of the mutant gene as well as intensity of lesion formation, lesion mutant plants were grown in the growth chamber at $15^{\circ} \mathrm{C}, 30^{\circ} \mathrm{C}$, and $45^{\circ} \mathrm{C}$ temperature having $14 \mathrm{~h}$ light and $10 \mathrm{~h}$ dark with $50 \%$ relative humidity from 30 days to 60 days of plant age. Plants grown in high temperature $\left(45^{\circ} \mathrm{C}\right)$ produced higher numbers of spots in all of the rice LMMs. However, the plants grown in $30^{\circ} \mathrm{C}$ and $15^{\circ} \mathrm{C}$ produced less number of spots (Fig. 3A). Data of spots number were documented from ten microscopic fields at $0.67 \mathrm{X}$ magnification of each leaf and five leaves from each plant at 60 days old. The average number of spots were increased about two fold in spll and spl5 mutants, and slightly increased in $s p l 3$ and spl4 mutants with the increasing degrees of temperature, whereas, spl6 mutant produced more than two fold increased spots grown under $45^{\circ} \mathrm{C}$ (Fig. $3 \mathrm{~A}$ and B).

The experiment using shading treatment showed that the lesions were dependent on light intensity. Effect of light intensity on lesion initiation and development was observed. To characterize this, a portion of fresh flag leaves of the plants were covered with aluminum foil prior to emerge visible spots and were let to grow further. After the for- 

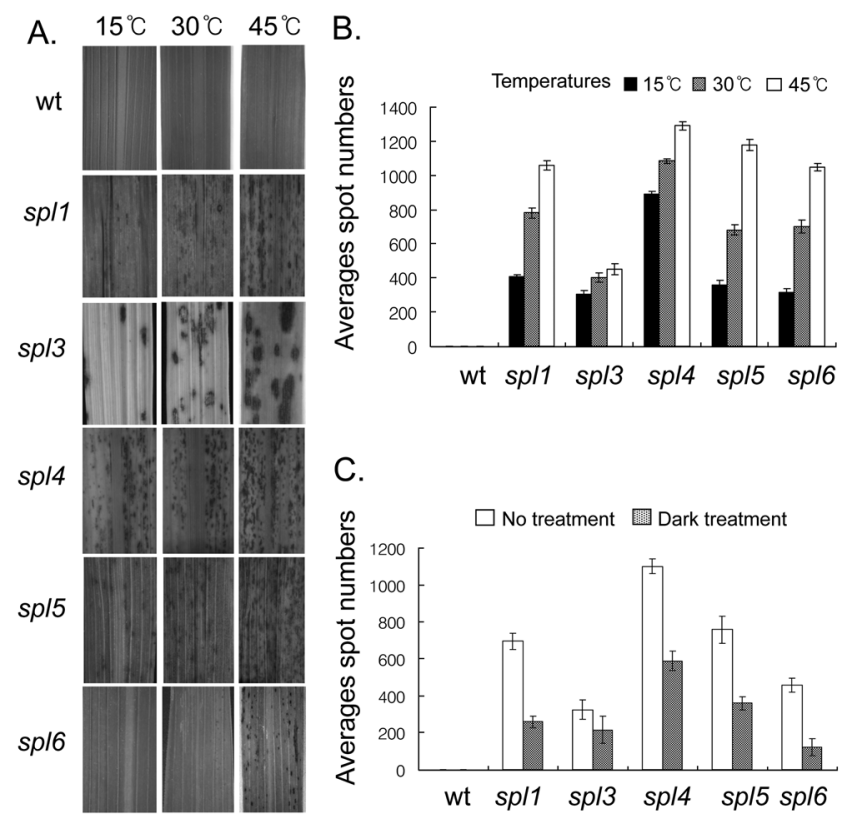

Fig. 3. Phenotype of lesion severity at diverse temperatures. (A) Representative figures of temperature induced spot severity of LMMs. The leaves of wild type plant (Ilpoombyeo, YUC044) and LMMs are indicated which were grown in $15^{\circ} \mathrm{C}, 30^{\circ} \mathrm{C}$ and $45^{\circ} \mathrm{C}$. Variations of temperature in each treatment were $\pm 2{ }^{\circ} \mathrm{C}$. Plants were grown in growth chamber at $14 \mathrm{~h} / 10 \mathrm{~h}$ day-night condition with $50 \%$ relative humidity and standard light intensity. Flag leaves of 60 days old plants were photographed using digital camera attached with simple microscope fixed at $1 \mathrm{X}$ magnification. (B) Data of average lesion quantity of rice LMMs. Plants were grown at $15^{\circ} \mathrm{C}, 30^{\circ} \mathrm{C}$, and $45^{\circ} \mathrm{C}$ in the growth chamber from 30 to 60 day old and spot numbers were documented from ten microscopic fields of each leaf. Average lesion quantity is mean of five leaves from each mutant. Lesion numbers are represented in the bar diagram. Values are the means \pm SE. (C) Distributions of the lesions quantity under dark treatment. Plants were kept in dark for 10 days before spot formation. Spot numbers were documented from ten microscopic fields of each leaf. Average lesion quantity is mean of five leaves from each mutant plant at 60 $\mathrm{d}$ old. Average number of spots are represented in the bar diagram. Values are the means $\pm \mathrm{SE}$ of spots quantity.

mation of severe spots on uncovered area, the foil was removed and lesion quantity was observed. The portion of leaves, which were covered with aluminum foil, lesions failed to develop, whereas lesions were severely developed on the uncovered area of the leaves (data not shown). Similar result was found when the plants were kept in the dark for 10 days prior to spot formation and were exposed to sunlight for further grow. Spots severity was compared with non treated LMMs at 60 days old. The dark treated plants produced very less number of spots than the plants having continuous exposure to the sunlight (Fig. 3C). These results indicating the intensity of sunlight prominently affects on the lesion formation and acceleration in the LLM plants.

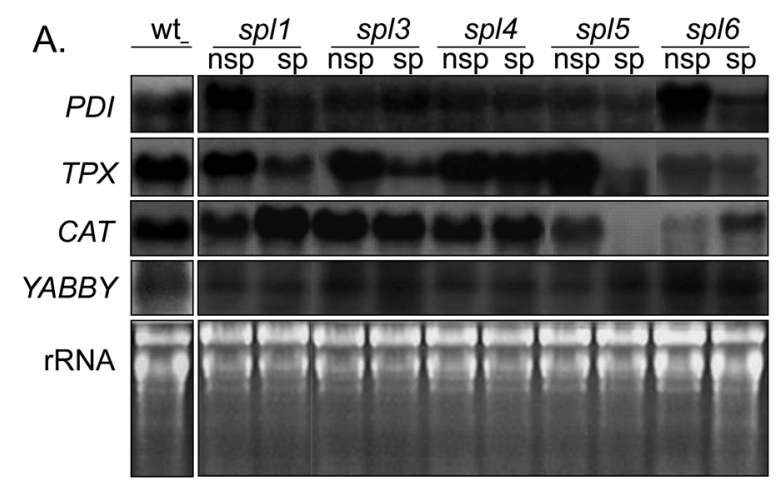

B.
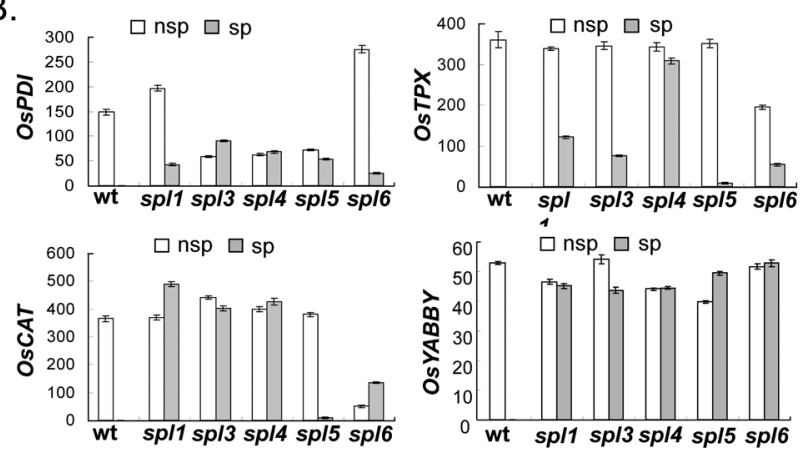

Fig. 4. Expression of the transcription levels of three genes in the spotted and nonspotted leaves of LMMs and wild type leaves of rice. (A) Representative Northern blot results of RNA gel. Genes of protein disulfide isomerase $(O S P D I)$, thioredoxin peroxidase $(O s T P X)$, catalase $(O s C A T)$ and YABBY gene $(O s Y A B B Y)$ were hybridized with nonspotted (nsp) and spotted (sp) leaves RNA of the mutants as well as fresh leaves (If) RNA of wild type (wt) plants at 60 days old. $O S Y A B B Y$ gene was used as experimental control. Twenty micrograms of total RNA were loaded in each lane. Ribosomal RNA bands are shown as loading controls for each RNA blot. Two independent experiments were performed. (B) Comparative intensities of the genes transcription levels in wild type leaves, and non spotted (nsp) and spotted (sp) leaves of the mutants. Values are the means $\pm \mathrm{SE}$ of transcription levels from two independent experiments. Fresh leaf samples were collected in liquid nitrogen from plants 60 days after transplantation.

Transcript levels of stress related genes of $O s P D I, O s T P X$ and $O s C A T$ in the lesion on the leaves of rice LMMs. In order to understand the involvement of stress related genes during lesion spot formation on the LMM mutants, the transcript levels of stress related genes, OsPDI, OsTPX and OsCAT were measured. The transcripts of $O s P D I$ were slightly increased in the non-spotted leaves of the spll and spl6 than those of wild type. Whereas, in the spll and spl6, the levels of $O s P D I$ transcripts in the spotted leaves were reduced less than two folds than those of the non-spotted leaves (Figs. 4A and B). The levels of OsTPX transcripts were reduced less than two folds in the spotted than those of the non-potted leaves in the spl1, spl3, spl5 and spl6 (Figs. $4 \mathrm{~A}$ and $\mathrm{B})$. Whereas, the levels of $O s T P X$ transcripts were 


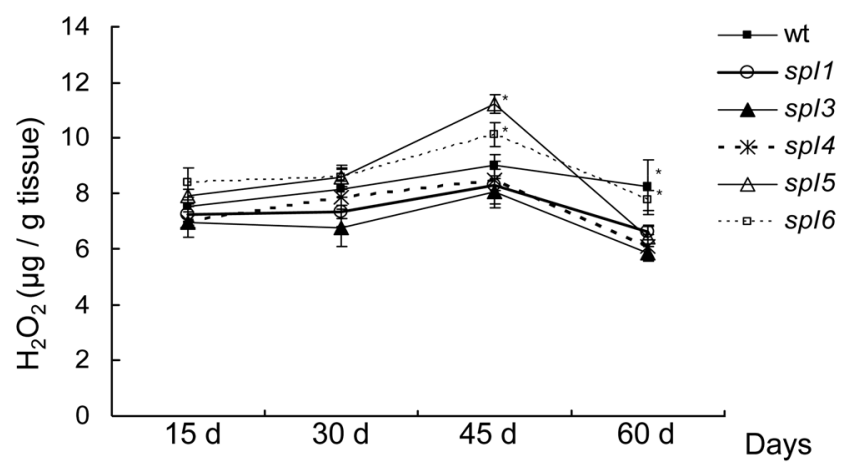

Fig. 5. Relative $\mathrm{H}_{2} \mathrm{O}_{2}$ concentrations in the spl1, spl3, spl4, spl5 and spl6 mutants occurring in the plants grown under natural condition. Asterisks indicate values that differ significantly from the control at $p<0.05$ (ANOVA; according to Duncan's multiple range test). Samples were used from 15, 30, 45, and 60 days old plants. Concentrations are expressed as $\mu \mathrm{g} / \mathrm{g}$ fresh tissue. Each value is the mean of three individual replicates ( \pm S.D.).

slightly reduced in the spotted leaves than those of the nonspotted leaves in the spl4 (Fig. 4, A and B). The levels of OsCAT transcripts were more increased in the lesion spotted leaves than those in the non-spotted leaves of the spl1, spl4 and spl6, but were not detectable in the spl5 (Fig. $4 \mathrm{~A}$ and $\mathrm{B}$ ). However, OsCAT transcript was slightly reduced in the spotted leaves than the non-spotted leaves in the sp13. As an experimental control, the patterns of $O s Y A B B Y$ gene, which involves in leaf morphogenesis, were observed. Interestingly, transcripts of $O s Y A B B Y$ gene were not degraded regardless in the mutants as well as wild type (Fig. 4, A and B).

Hydrogen peroxide accumulations in the leaves of rice LMMs. The levels of total hydrogen peroxide $\left(\mathrm{H}_{2} \mathrm{O}_{2}\right)$ were monitored in the LMM plants at different times in relation to lesion formation. Hydrogen peroxide was extracted from upper most leaves of 15, 30, 45 and 60 days old plants of LMMs and wild type (Fig. 5). Up to 15 days, in the absence of lesions, $s p l$ mutant showed similar levels of $\mathrm{H}_{2} \mathrm{O}_{2}$ to the wild type, whereas, $\mathrm{H}_{2} \mathrm{O}_{2}$ level was slightly elevated at 30 days when lesions were initiated and was elevated nearly 3fold at 45 day in the mutant when lesion are started to expand (Fig. 5). However, $\mathrm{H}_{2} \mathrm{O}_{2}$ levels of the mutant leaves were reduced at 60 days when severe lesions appeared. Interestingly, in the wild type, $\mathrm{H}_{2} \mathrm{O}_{2}$ levels were elevated to a slighter degree by all stages, where highest accumulation was found at 45 days and were slightly reduced at 60 days (Fig. 5).

\section{Discussion}

The patterns of lesion formation were regulated genetically and developmentally among the rice LMMs.
Similar with most of the lesion mimic mutants in rice and maize, the lesion formation in the studied LMMs was found developmentally regulated (Matin et al., 2006). In most cases lesions first appear as tiny specks near the tip of the leaf on the upper side and then these lesions extend to downward and on both of the leaf surfaces which simultaneously produce yellowish black spots of dead necrotic cells that finally become visible on both surfaces of the leaf (Fig. 1A). Interestingly, newly formed flag leaves of the LMMs remain non-spotted, however, matured flag leaves and old leaves become severely spotted (Fig. 1). Similar lesion formation was observed in wheat $l l s l$ mutant where leaf tip of older leaves become spotted first than extend all of the leaf (Simmons et al., 1998).This severe lesion development in the flag and old leaves may correlated with more active photosynthesis producing more ROS resulting in mesophyll cell disruption in the flag leaves. Here, we also observed, the levels of hydrogen peroxide were decreased in the 60 days old lesion developed leaves of rice LMMs (Fig. 5). However, we found that the amount of catalase transcripts were increased in spotted leaves of spll, spl3, spl4 and spl6 (Fig. 4, A and B). Therefore, we assumed that even lesion developed on the old leaves by accumulation of ROS resulting from the high photosynthesis rate, catalase actively decomposed the hydrogen peroxide through their over expression, thus reducing the amount of hydrogen peroxide. Therefore, we presumed catalase is not directly linked genes controlling LMM phenotypes of spll, spl3, spl4 and spl6. However, lesion development in $s p l 5$ may be involved with catalase because of low level of catalase transcripts (Fig. 4, A and B). This suggested that the examined rice LMMs may be caused by different mutant genes involvement resulting in a unique phenotype of their lesion formation. Therefore, we concluded patterns of lesion formation of rice spll, spl3 spl4, spl5 and spl6 mutants were presumably developmentally regulated depending upon their own genetic programs which carried out by homozygous recessive only (Table 2).

\section{Stresses are the effective factors for lesion development} in the LMMs. We had a question how the spot formation in rice LMMs is affected by increasing temperature. We observed the degree of spots severity with increasing temperature. As shown in the Fig. 3, the degree of temperature is clearly an effective factor for the spot formation of the LMMs. Usually, plants at high temperature increase the rate of photosynthesis. During this process, high levels of photo oxidation produce excessive amount of ROS. Similar result was found in $s p l 7$ mutant where temperature was the causal agent for spot formation and expression (Yamanouchi et al., 2002). The spl7 mutant showed variable lesion density in various temperature conditions where lesion density 
decreased in low temperature. Again, we discussed that accelerated accumulation of ROS by active photosynthesis in the mesophyll cells might break down thylakoid membrane in the chloroplast leading to the cell death (Kang et al., 2007). In this report, we found in rice spotted leaf mutants of LMMs including spll, spl3, spl4, spl5and spl6 that temperature also might be one of the causal agents for spot formation and expression (Fig. 3).

Genes related to oxidative stress were differentially regulated in the LMMs. In order to understand the relationships between spot formation and stress related genes, we examined levels of gene expressions of thioredoxin peroxidase (OsTPX, accession: AM039889), catalase (OsCAT, accession AY339372) and protein disulfide isomerase (OsPDI, accession: AY987391). As figure 4 showed that the level of TPX transcripts were reduced in all of the spotted leaves compared to non-spotted leaves. This indicates that rice LMMs might cause the failure to protect the increased level of ROS. The protein thioredoxin peroxidase (TPX) reduces the hydrogen peroxide $\left(\mathrm{H}_{2} \mathrm{O}_{2}\right)$ through intracellular redox signaling pathway (Schröder et al., 1998). Upon accumulation of ROS during stress exposure, $T P X$ protect the chloroplasts against oxidative damage by reducing ROS (Hiraga et al., 2001). The protein PDI helps in the formation and rearrangement of disulfide bonds in newly synthesized proteins and lack of $P D I$ may reduce the amount of nucleotide production through pentose phosphate pathway (PPP) and limit chaperone activity (Bulleid, 1993; Puig \& Gilbert, 1994). In some cases, simple analysis of representative gene expression is very useful in the main physiological pathways. We assumed that TPX and CAT genes are involved in ROS scavenging system and $P D I$ involved in refolding proteins system as house-keeping protection system. Thus, we could predict how lesion formation is related with direct failure of ROS scavenging system or house-keeping protein protection system. In our observations, the level of $P D I$ transcriptions in the spotted leaves of spll and spl6 mutants were reduced than those of the non-spotted leaves (Fig. 4). This might be the effects that the $P D I$ in the mutants could not help in refolding the denatured proteins during stresses. However, there were no significant variation of PDI transcriptions in the spl3, spl4 and spl5 comparing with between their non-spotted leaves and spotted leaves. This may have indicated that different genetic mechanisms exist in expression of phenotypes of lesion development depending upon genotypes of LMMs.

Chlorophyll amounts decreased along with lesion severity in the LMMs. Chlorophyll is a photosynthetic pigment which is positively correlated with photosynthetic rate (Davis et al., 1979). It is identified that, chlorophyll content usually increase with increasing age and at the later stage during senescence, chlorophyll content tent to decrease slightly in the rice (Wang et al., 2008). However, observation through spectrophotometer revealed that differences of chlorophyll content in the wild type upon plant age is not significant, whereas, highly significant differences found in the mutants which might be resulted from the degradation of chloroplasts in the mutants. In previous research we found thylakoid membrane in spl6 mutant were broken resulting in destruction of membrane and lamella structures in chloroplast and may caused leaking chlorophylls. This disruption of thylakoid membrane in the chloroplast leading to the cell death was hypothesized by Kang et al. (2007).

$\mathrm{H}_{2} \mathrm{O}_{2}$ accumulation might accelerate lesion formation in the LMMs. Endogenous peroxide concentration in leaves were measured using a titanium assay method, by complexing the hydrogen peroxide with titanium $\left(\mathrm{Ti}^{4+}\right)$ ion and precipitating the complex in alkaline solution. Hydroperoxides form a specific complex with titanium which could be measured by colorimetry (Macnevin and Uron, 1953) at $415 \mathrm{~nm}$. Production of $\mathrm{H}_{2} \mathrm{O}_{2}$ in the cells due to oxidative burst is the prominent evidence caused by cell death. The accumulation of $\mathrm{H}_{2} \mathrm{O}_{2}$ in and around the cells was observed in many LMMs (Lorrain et al., 2003). As we showed in Fig. 5, the level of hydrogen peroxide was correlated with the lesion formation in the mutants. At the early stage, $\mathrm{H}_{2} \mathrm{O}_{2}$ level was similar with wild type, however, suddenly increased to high level in the mutants at 45 days, the stage when lesion spots were appeared severely indicating, $\mathrm{H}_{2} \mathrm{O}_{2}$ reached to toxic level thus plants are initiated programmed cell death leading to spot formation. The level of $\mathrm{H}_{2} \mathrm{O}_{2}$ might be reduced after significant cell death in 45 days, therefore, reduced level of $\mathrm{H}_{2} \mathrm{O}_{2}$ was found at 60 days old mutant plant (Fig. 5). Similar result was found that high accumulation of $\mathrm{H}_{2} \mathrm{O}_{2}$ in maize leaves was observed during chilling stress then reduced after cell death progressed (Anderson et al., 1995). Another example suggested that the levels of $\mathrm{H}_{2} \mathrm{O}_{2}$ in the root cell death in rice were increased up to a certain time and then were decline upon cadmium exposure (Guo et al., 2009).

Since it has been demonstrated that most rice LMMs, like spl1, spl17, Spl26, have resistance against rice fungal blast and bacterial blight (Mizobuchi et al., 2002; Takahashi et al., 1999; Wu et al., 2008; Yin et al., 2000) and evolved in the control of plant cell death and defense (Zeng et al., 2004), studied genetics of LMMs in plants might be an important tool to figure out the molecular mechanism of cell death and defense against both biotic, pathogenic and abiotic stresses. Therefore, these spontaneous lesion mimic mutants will be providing lots of information for molecular 
interactions between plants and microorganisms. Regarding to the most important agronomic traits, LMMs showed a lower trait values when comparing with wild type control because of malfunction of photosynthesis in the damaged leaves. Thus, study on practices using the mechanism of genetic lesion mutants would be a great interest in prevention of stress-induced senescence which might be an important target in crop yield improvement.

\section{Acknowledgements}

We thank Professor Hak Soo Suh at Yeungnam University for his assistants. This work was supported by the Yeungnam University Research Grant (207A-235-165) in 2007 for Dr. Sang Gu Kang.

\section{References}

Anderson, M. D., Prasad, T. K. and Stewart, C. R. 1995. Changes in isozyme profiles of catalase, peroxidase, and glutathione reductase during acclimation to chilling in mesocotyls of maize seedlings. Plant Physiol. 109:1247-1257.

Balague, C., Lin, B., Alcon, C., Flottes, G., Malmstrom, S., Kohler, C., Neuhaus, G, Pelletier, G, Gaymard, F. and Roby, D. 2003. HLM1, an essential signaling component in the hypersensitive response, is a member of the cyclic nucleotidegated channel ion channel family. Plant Cell 15:365-379.

Bouchez, O., Huard, C., Lorrain, S., Roby, D. and Balagué, C. 2007. Ethylene is one of the key elements for cell death and defense response control in the Arabidopsis lesion mimic mutant vad1. Plant Physiol. 145:465-477.

Brennan, T. and Frenkel, C. 1977. Involvement of hydrogen peroxide in the regulation of senescence in pear. Plant Physiol. 59:411-416.

Bulleid, N. J. 1993. Protein disulfide isomerase: role in biosynthesis of secretory proteins. Adv. Protein Chem. 44:125-150.

Buschges, R., Hollricher, K., Panstruga, R., Simons, G, Wolter, M., Frijters, A., van Daelen, R., van der Lee, T., Diergaarde, P., Groenendijk, J., Topsch, S., Vos, P., Salamini, F. and Schulze-Lefert, P. 1997. The barley Mlo gene: a novel control element of plant pathogen resistance. Cell 7:695-705.

Chory, J., Peto, C. A., Ashbaugh, M., Saganich, R., Pratt, L. and Ausubel, F. 1989. Different roles for phytochrome in etiolated and green plants deduced from characterization of Arabidopsis thaliana mutants. Plant Cell 1:867-880.

Davis, M. S., Forman, A. and Fajer, J. 1979. Ligated chlorophyll cation radicals: their function in photosystem II of plant photosynthesis. Proc. Natl. Acad. Sci. USA 76:4170-4174.

Dietrich, R. A., Delaney, T. P., Uknes, S. J., Ward, E. R., Ryals, J. A. and Dangl, J. L. 1994. Arabidopsis mutants simulating disease resistance response. Cell 77:565-577.

Gray, J., Close, P. S., Briggs, S. P. and Johal, G S. 1997. A novel suppressor of cell death in plants encoded by the Lls 1 gene of maize. Cell 89:25-31.

Gray, J., Janick-Buckner, D., Buckner, B., Close, P. S. and Johal,
G S. 2002. Light-dependent death of maize $l l s 1$ cells is mediated by mature chloroplasts. Plant Physiol. 130:1894-1907.

Greenberg, J. T. 1996. Programmed cell death: A way of life for plants. Proc. Natl. Acad. Sci. USA 93:12094-12097.

Greenberg, J. T. and Ausubel, F. M. 1993. Arabidopsis mutants compromised for the control of cellular damage during pathogenesis and aging. Plant J. 4:327-341.

Guo, B., Liang, Y. and Zhu, Y. 2009. Does salicylic acid regulate antioxidant defense system, cell death, cadmium uptake and partitioning to acquire cadmium tolerance in rice?. J. Plant Physiol. 166:20-31.

Hiraga, S., Sasaki, K., Ito, H., Ohashi, Y. and Matsui, H. 2001. A large family of class III plant peroxidases. Plant Cell Physiol. 42:462-468.

Hoisington, D. A., Neuffer, M. G. and Walbot, V. 1982. Disease lesion mimics in maize. 1. Effect of genetic background, temperature, developmental age, and wounding on necrotic spot formation with Les 1. Dev. Biol. 93:381-388.

Hu, G., Yalpani, N., Briggs, S. P. and Johal, G. S. 1998. A porphyrin pathway impairment is responsible for the phenotype of a dominant disease lesion mimic mutant of maize. Plant Cell 10:1095-1105.

Jabs, T., Dietrich, R. A. and Dangl, J. L. 1996. Initiation of runway cell death in an Arabidopsis mutant by extra cellular superoxide. Science 273:1853-1856.

Jambunathan, N., Siani, J. M. and McNellis, T. W. 2001. A humidity-sensitive Arabidopsis copine mutant exhibits precocious cell death and increased disease resistance. Plant Cell 13:2225-2240.

Kang, S. G, Jeong, H. K. and Suh, H. S. 2004. Characterization of a new member of the glutathione peroxidase gene family in Oryza sativa. Mol. Cells 17:23-28.

Kang, S. G., Matin, M. N., Bae, H. H. and Natarajan, S. 2007. Proteome analysis and characterization of phenotypes of lesion mimic mutant spotted leaf 6 in rice. Proteomics 7:2447-2458.

Lee, E. T., Koo, B. J., Jung, J. H., Chang, M. U. and Kang, S. G. 2007. Detection of allexiviruses in the garlic plants in Korea. Plant Pathol. J. 23:266-271.

Liu, G, Wang, L., Zhou, Z., Leung, H., Wang, G. L. and He, C. 2004. Physical mapping of a rice lesion mimic gene, Spll, to a $70-\mathrm{kb}$ segment of rice chromosome 12. Mol. Genet. Genomics 272:108-115.

Lorrain, S., Vailleau, F., Balague, C. and Roby, D. 2003. Lesion mimic mutants: keys for deciphering cell death and defense pathways in plants?. Trends Plant Sci. 8:263-271.

Mackinney, G. 1941. Absorption of light by chlorophyll solutions. J. Biol. Chem. 140:315-322.

Macnevin, W. M. and Uron, P. F. 1953. Separation of hydrogen peroxide from organic hydroperoxides. Anal. Chem. 25:17601761.

Matin, M. N., Suh, H. S. and Kang, S. G. 2006. Characterization of phenotypes of rice lesion resembling disease mutants. Korean J. Genet. 28:221-228.

Mittler, R., Vanderauwera, S., Gollery, M. and Van Breusegem, F. 2004. Reactive oxygen gene network of plants. Trends Plant Sci. 9:490-496. 
Mizobuchi, R., Hirabayashi, H., Kaji, R., Nishizawa, Y., Yoshimura, A., Satoh, H., Ogawa, T. and Okamoto, M. 2002. Isolation and characterization of rice lesion-mimic mutants with enhanced resistance to rice blast and bacterial blight. Plant Sci. 163:345353.

Mori, M., Tomita, C., Sugimoto, K., Hasegawa, M., Hayashi, N., Dubouzet, J. G., Ochiai, H., Sekimoto, H., Hirochika, H. and Kikuchi, S. 2007. Isolation and molecular characterization of a Spotted leaf 18 mutant by modified activation-tagging in rice. Plant Mol. Biol. 63:847-860.

Noutoshi, Y., Kuromori, T., Wada, T., Hirayama, T., Kamiya, A., Imura, Y., Yasuda, M., Nakashita, H., Shirasu, K. and Shinozaki, K. 2006. Loss of necrotic spotted lesions 1 associates with cell death and defense responses in Arabidopsis thaliana. Plant Mol. Biol. 62:29-42.

Puig, A. and Gilbert, H. F. 1994. Protein disulfide isomerase exhibits chaperone and anti-chaperone activity in the oxidative refolding of lysozyme. J. Biol. Chem. 269:7764-7771.

Rostoks, N., Schmierer, D., Mudie, S., Drader, T., Brueggeman, R., Caldwell, D. G, Waugh, R. and Kleinhofs, A. 2006. Barley necrotic locus necl encodes the cyclic nucleotide-gated ion channel 4 homologous to the Arabidopsis HLM1. Mol. Genet. Genomics 275:159-168.

Schröder, E. and Pointing, C. P. 1998. Evidence that peroxiredoxins are novel members of the thioredoxin fold superfamily. Protein Sci. 7:2465-2468.

Simmons, C., Hantke, S., Grant, S., Johal, G. S. and Briggs, S. P. 1998. The maize lethal leaf spot 1 mutant has elevated resistant to fungal infection at the leaf epidermis. Mol. Plant Microbe Interact. 11:1110-1118.

Sugie, A., Murai, K. and Takumi, S. 2007. Alteration of respiration capacity and transcript accumulation level of alternative oxidase genes in necrosis lines of common wheat. Genes Genet. Syst. 82:231-239.
Takahashi, A., Kawasaki, T., Henmi, K., Shii, K., Kodama, O., Satoh, H. and Shimamoto, K. 1999. Lesion mimic mutants of rice with alterations in early signaling events of defense. Plant J. 17:535-545.

Wang, F., Wang, G, Li, X., Huang, J. and Zheng, J. 2008. Heredity, physiology and mapping of a chlorophyll content gene of rice (Oryza sativa L.). J. Plant Physiol. 165:324-330.

Wolter, M., Hollricher, K., Salamini, F. and Schulze-Lefert, P. 1993. The mlo resistance alleles to powdery mildew infection in barley trigger a developmentally controlled defense mimic phenotype. Mol. Gen. Genet. 239:122-128.

Wu, C., Bordeos, A., Madamba, M. R., Baraoidan, M., Ramos, M., Wang, G L., Leach, J. E. and Leung, H. 2008. Rice lesion mimic mutants with enhanced resistance to diseases. Mol. Genet. Genomics 279:605-619.

Yamanouchi, U., Yano, M., Lin, H., Ashikari, M. and Yamada, K. 2002. A rice spotted leaf gene, $S p l 7$, encodes a heat stress transcription factor protein. Proc. Natl. Acad. Sci. USA 99:75307535.

Yao, Q., Zhou, R., Fu, T., Wu, W., Zhu, Z., Li, A. and Jia, J. 2009. Characterization and mapping of complementary lesionmimic genes $\operatorname{lm} 1$ and $\operatorname{lm} 2$ in common wheat. Theor. Appl. Genet. 119:1005-1012.

Yin, Z., Chen, J., Zeng, L., Goh, M., Leung, H., Khush, G S. and Wang, G L. 2000. Characterizing rice lesion mimic mutants and identifying a mutant with broad-spectrum resistance to rice blast and bacterial blight. Mol. Plant Microbe Interact. 13:869-876.

Zeng, L. R., Qu, S., Bordeos, A., Yang, C., Baraoidan, M., Yan, H. and Xie, Q. 2004. Spotted leaf11, a negative regulator of plant cell death and defense, encodes a U-Box/Armadillo repeat protein endowed with E3 ubiquitin ligase activity. Plant Cell 16:2795-2808. 